\title{
A Fuzzy Rule-Based Expert System for Evaluating Intellectual Capital
}

\author{
Mohammad Hossein Fazel Zarandi, ${ }^{1}$ Neda Mohammadhasan, ${ }^{1}$ and Susan Bastani ${ }^{2}$ \\ ${ }^{1}$ Department of Industrial Engineering, Amirkabir University of Technology, P.O. Box 15875-4413, Tehran, Iran \\ ${ }^{2}$ Department of Social Sciences, Alzahra University, P.O. Box 1993891176, Tehran, Iran \\ Correspondence should be addressed to Mohammad Hossein Fazel Zarandi, zarandi@aut.ac.ir
}

Received 17 April 2012; Accepted 30 August 2012

Academic Editor: Zeng-Guang Hou

Copyright ( 2012 Mohammad Hossein Fazel Zarandi et al. This is an open access article distributed under the Creative Commons Attribution License, which permits unrestricted use, distribution, and reproduction in any medium, provided the original work is properly cited.

\begin{abstract}
A fuzzy rule-based expert system is developed for evaluating intellectual capital. A fuzzy linguistic approach assists managers to understand and evaluate the level of each intellectual capital item. The proposed fuzzy rule-based expert system applies fuzzy linguistic variables to express the level of qualitative evaluation and criteria of experts. Feasibility of the proposed model is demonstrated by the result of intellectual capital performance evaluation for a sample company.
\end{abstract}

\section{Introduction}

Today's "new economy" is actually the "knowledge economy" or the "knowledge society". This development is characterized by increased digitalization, globalization, and application of knowledge [1]. Intellectual capital consists of assets created through intellectual activities ranging from acquiring new knowledge (learning) and inventions to creating valuable relationships [2]. In strategy decisionmaking, an intellectual capital evaluation model should be a feasible tool for managers to handle and improve existing intellectual capital effectively and efficiently in accordance with different performance levels of each item and criterion [1].

Tai and Chen [3] proposed a feasible enterprise intellectual capital evaluation model by means of 2-tuple fuzzy linguistic approach to assist managers understand the performance of intellectual capital. In this model, experts apply linguistic variables to express the level of intellectual items. Fasanghari et al. [4] proposed a fuzzy expert system which can measure intellectual capital based on three categories: knowledge capital, management capital, and market capital. This expert system uses 27 rules to assess level of intellectual capital based on these three components. However, these measurement models help enterprise managers to understand the status of intellectual capital, but they frequently use the term "intellectual capital" and its items in an allencompassing fashion with the risk that in time the identity of object will become unclear [5]. Managers are faced with many questions such as: "what is intellectual capital?", "what does employee's knowledge mean?", "how can I found out the level of employee's knowledge in my company?", or "is employee's knowledge important for my company?" a set of rules which determine the level of intellectual capital items by asking some questions from managers is useful. Manager's answer to these questions is expressed with linguistic labels. Here, we deal with a qualitative model as a system model based on linguistic description. Sugeno and Yasukawa [6] defined fuzzy modeling as a qualitative modeling scheme by which we quantitatively describe system behavior using a natural language. Thus, a suitable fuzzy expert system, which could identifies the performance degree of intellectual capital, is proposed.

The proposed fuzzy rule-based expert system evaluates the performance degree of intellectual capital based on the model proposed by Tai and Chen [3] using performance level and importance level of each intellectual item. In this expert system, the importance and performance level of each 
intellectual item are determined indirectly through asking some questions from managers.

The main contributions of this paper are as follows.

(i) Instead of asking managers directly about the status of enterprise's intellectual items-so as previous works - the importance and performance level of each intellectual capital is determined indirectly through asking some question.

(ii) Developing two sets of rules (totally about 80 rules) for each intellectual capital items to assess the overall status of intellectual capital more efficiently (one rule set for importance level and one for performance level).

This paper is organized as follows. Section 2 introduces the concept of intellectual capital and fuzzy control rules. In Section 3, proposed fuzzy expert system to evaluate intellectual capital is presented. In Section 4, the proposed system is implemented in a real company. Finally, some conclusions and future works are presented at the last section of the paper.

\section{Background}

2.1. Intellectual Capital (IC). Edvinsson and Malone [7] define the difference between a firm's market value and book value as the value of intellectual capital. Stewart [8] defines intellectual capital as "intellectual material-knowledge, information, intellectual property, experience-that can be put to use to create wealth". He recognizes human capital, structure capital, and customer capital. Sveiby [9] proposed that intellectual capital includes employee competence, internal structure, and external structure. Edvinsson [10] divides structure capital into organization capital and customer capital. Liebowitz and Wright [11] divide intellectual capital into four unique categories such as human capital, customer capital, process capital, and innovation capital. Organization for Economic Cooperation and Development (OECD) [12] describes intellectual capital as "the economic value of two categories of intangible assets of a company: (1) organizational ("structural") capital and (2) human capital". Bukh et al. [13] identify that in most models of intellectual capital, human capital, customer capital, and organization capital are the components of intellectual capital.

Human capital is the foundation of IC, a primary element to perform IC's functions. It refers to such factors as employee's knowledge, skill, capability, and attitudes in relation to fostering performances which customers are willing to pay for and the company's profit comes from. Customer capital, which acts as a bridge and a catalyst on the operations of IC, is the main requirement and determinant in converting IC into market value and thereupon organization business performance [14]. Structural capital is the use of the part of the intellectual capital that is owned by the company. Edvinsson [6] defines the term as: "Hardware, software, databases, organizational structure, patents, trademarks, and everything else of organizational capability that supports that employee's productivity. Everything left at the office, when the employees go home. Unlike human capital, structural capital can be owned and thereby traded."

To evaluate the overall performance of intellectual capital, we should define the performance of intellectual capital components. So, by reviewing the literature, the following classification is used in this paper: human capital can be defined as a combination of employee's knowledge, employee's innovativeness, satisfaction degree, and employee's turnover rate. Customer capital can be classified into market share rate, customer loyalty, customer satisfaction, and customer relationship. Structural capital can be classified into trademark, operation process, information system, and corporate culture. By defining the performance degree of each item, we can evaluate the performance degree of intellectual capital. The importance and performance degree of each intellectual item is determined with linguistic variables. Fuzzy set theory is suitable in qualitative assessment. So for each intellectual item, we define a fuzzy rule set to evaluate the item through asking question from managers.

2.2. Fuzzy Control Rules. Conventional rule-based expert systems use human expert knowledge to solve real-world problems that normally would require human intelligence. Expert knowledge is often represented in the form of rulesor as datawithin the computer. Depending upon the problem requirement, these rules and data can be recalled to solve problems [15]. Some of the important advantages of expert systems are as follows [16]:

(i) ability to capture and preserve irreplaceable human experience;

(ii) ability to develop a system more consistent than human experts;

(iii) minimize human expertise needed at a number of locations at the same time (especially in a hostile environment that is dangerous to human health);

(iv) solutions can be developed faster than human experts.

The basic components of an expert system are illustrated in Figure 1. The knowledge base stores all relevant information, data, rules, cases, and relationships used by the expert system. A knowledge base can combine the knowledge of multiple human experts. A rule is a conditional statement that links given conditions to actions or outcomes [16].

Zadeh [17] states that precise qualitative analyses of the behavior of humanistic systems are not likely to have much relevance to the real-world societal, political, economic, and other types of problems which involves humans either as individuals or in groups. He suggested linguistic analysis in place of quantitative analysis. Mamdani was the first to apply fuzzy logic to control (Figure 2). This topic became known as fuzzy algorithmic control or linguistic control. Fuzzy control can be viewed as a result of qualitative modeling of a human operator. 


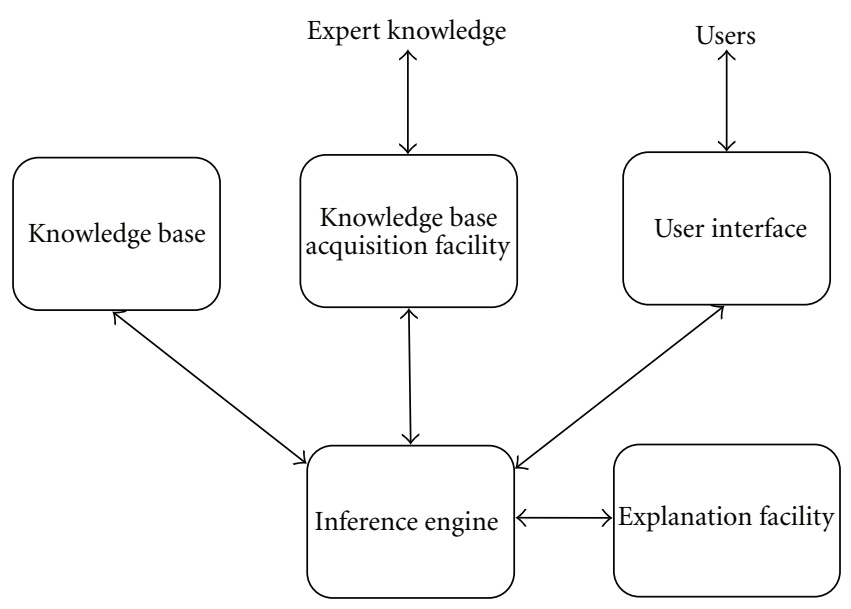

Figure 1: Architecture of a simple expert system [16].

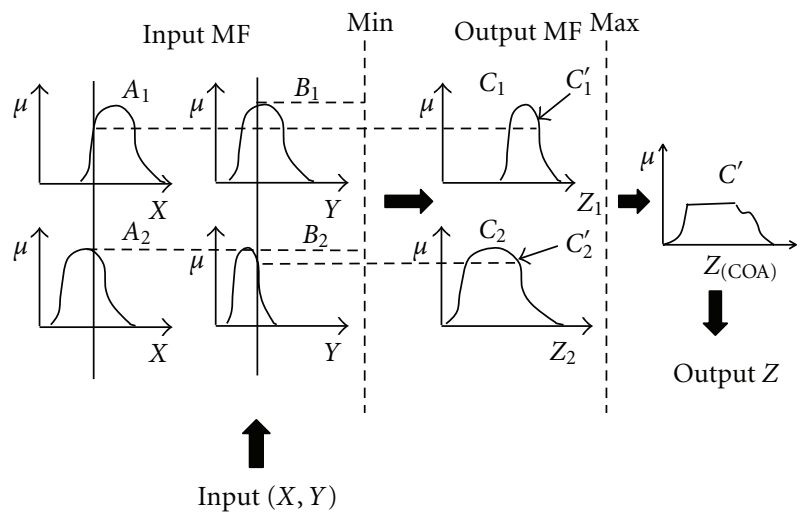

FIgure 2: Mamdani fuzzy inference system using min and max for $t$-norm and $t$-conorm operators [16].

\section{Proposed Fuzzy Expert System to Evaluate Intellectual Capital Performance}

3.1. Overview of the Problem Domain. Intellectual capital is intangible, and assessing its components needs knowledge of intellectual capital experts. In knowledge economy, enterprises should manage their intellectual capital to maintain their competitive advantage in capital market. To manage intellectual capital, enterprises should measure it. In this paper, we have developed a fuzzy rule base expert system for this purpose. Using knowledge of intellectual capital experts, this expert system helps enterprise decision makers to determine organization's performance degree of intellectual capital. Fuzzy expert system models are similar to the classical expert system models, where input spaces are mapped to an output space. A fuzzy expert system uses a collection of fuzzy membership functions and rules for knowledge representation and reasoning with observed system state data. An approximate reasoning process in a fuzzy expert system is executed as follows [18]. Fuzzification and forming a fuzzy set is a sub process in a fuzzy expert system:

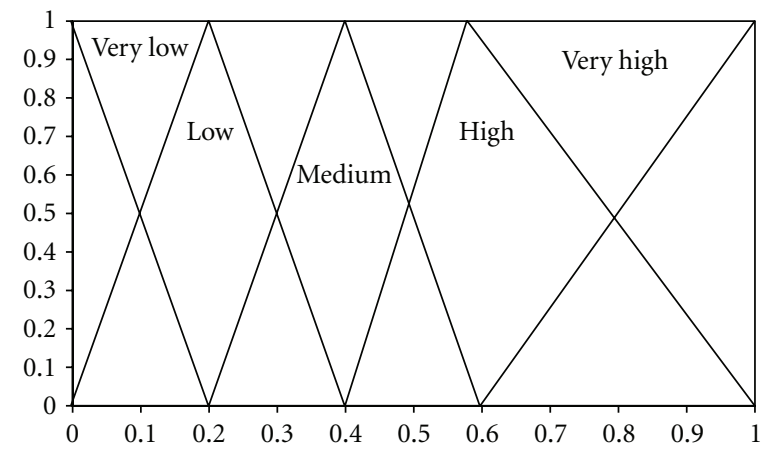

FIGURE 3: Fuzzy sets on proportion of staff with a university degree.

$\left(a_{1}\right)$ Fuzzification. The degree of the memberships for each rule's premise is determined by matching the linguistic terms with the actual values of the input variables [18]. For example, in the proposed evaluation model, "Proportion of staff with a university degree" is the linguistic variable, and "high" is one of its fuzzy sets. A fuzzy set can be formed by assigning a membership value to each object in the interval of $[0,1]$. Membership values represent the degree to which an object belongs to a fuzzy set. Let $X$ denotes the universe of discourse, where $x$ represents an element of the universe, $X$ and $A$ denote a fuzzy set. A fuzzy set is hence characterized by its membership function, $\mu_{A}(x)$ as [19]

$$
\mu_{A}(x): X \rightarrow[0,1] .
$$

Membership function states that values assigned to the elements of the universal set, $X$, fall within a specified range. In the meantime, it indicates the membership grade of these elements in fuzzy set $A$. A fuzzy set $A$, on universe of discourse of $X$, can also be defined as a set of ordered pairs as [19]

$$
A=\left\{\left(x, \mu_{A}(x)\right) \mid x \in X\right\} .
$$

Figure 3 shows membership functions of fuzzy sets "very low", "low”, “medium”, "high”, and “very high”. Horizontal 
axis of graph in Figure 3 represents "proportion of staff with university degree" in percentage (the universal set $X$ ) and vertical axis represents the degree to which this proportion for a company can be labeled "very low", "low", "medium", "high", and "very high".

$\left(a_{2}\right)$ Forming Fuzzy Sets. To represent a fuzzy set in a computer, we need to define its membership function. One approach is to poll a group of people for their understanding of the term that we are attempting to represent by the fuzzy set [20]. For example, consider the concept of high proportion of staff with university degree. We could ask intellectual capital experts to what degree they believe a proportion of staff with university degree is high. After acquiring answers for a range of proportions, we could perform simple averaging to produce a fuzzy set of high proportion of staff with university degree. We can now use this function to ascribe a belief (or membership value) to a given proportion belonging to the fuzzy set of high. We could continue this polling to account for other proportion descriptions such as very low, low, medium, and very high (as shown in Figure 3).

Using linguistic variables in fuzzy expert systems make all modules of a classical expert system fuzzy.

$\left(b_{1}\right)$ Fuzzy Knowledge Acquisition. This module involves the adaption of the expert system to a specific domain. Zimmerman [18] state that the goal of this module is extracting and organizing the knowledge and expertise embedded in the problem domain. Knowledge acquisition is described in literature as the most difficult process, one of the greatest difficulties, the biggest bottleneck, or the most time consuming task. There is no all-encompassing, unified theory of how to acquire knowledge, and probably never will be [21].

In this paper, we use direct approach for knowledge acquisition process. Direct approach or interviewing is good for obtaining a sense of the knowledge domain [21]. Interviewing consists of asking the domain experts questions about the domain of interest and how they perform their tasks [22].

To obtain the knowledge of intellectual capital from the experts, we provided them with a set of indicators which may be included in an intellectual capital statement. We used a structured interview in which the experts were asked to determine which of these indicators have impact on importance and performance of which intellectual capital components. Next, the experts were asked to determine to what degree they are effective on outputs. Finally, they were asked to connect indicators to one another, outputs to one another, and indicators to outputs through rules. For example, intellectual capital experts believe that proportion of staff with a university degree is positively related with employee's knowledge capital, so, for instance, one of the extracted rules is as follows: IF proportion of staff with a university degree is very low, THEN employee's knowledge degree is very poor.
TABLE 1: Fuzzy rule set for employee's knowledge performance degree.

\begin{tabular}{|c|c|}
\hline \multicolumn{2}{|l|}{$\mathrm{K}-1-1$} \\
\hline IF & Proportion of staff with a university degree is very low \\
\hline THEN & Employee's knowledge degree is (VP). \\
\hline \multicolumn{2}{|l|}{$\mathrm{K}-1-2$} \\
\hline IF & Proportion of staff with a university degree is low \\
\hline THEN & Employee's knowledge degree is $(\mathrm{P})$. \\
\hline \multicolumn{2}{|l|}{$\mathrm{K}-1-3$} \\
\hline IF & Proportion of staff with a university degree is medium \\
\hline THEN & Employee's knowledge degree is $(\mathrm{F})$. \\
\hline \multicolumn{2}{|l|}{ K-1-4 } \\
\hline IF & Proportion of staff with a university degree is high \\
\hline AND & Proportion of $30-50$ age employees is low \\
\hline THEN & Employee's knowledge degree is $(\mathrm{F})$. \\
\hline \multicolumn{2}{|l|}{ K-1-5 } \\
\hline IF & Proportion of staff with a university degree is high \\
\hline AND & Proportion of $30-50$ age employees is medium \\
\hline THEN & Employee's knowledge degree is $(\mathrm{G})$. \\
\hline \multicolumn{2}{|l|}{ K-1-6 } \\
\hline IF & Proportion of staff with a university degree is high \\
\hline AND & Proportion of $30-50$ age employees is high \\
\hline THEN & Employee's knowledge degree is (VG). \\
\hline \multicolumn{2}{|l|}{ K-1-7 } \\
\hline IF & Proportion of staff with a university degree is very high \\
\hline AND & Proportion of $30-50$ age employees is low \\
\hline THEN & employee's knowledge degree is $(\mathrm{F})$. \\
\hline \multicolumn{2}{|l|}{$\mathrm{K}-1-8$} \\
\hline IF & Proportion of staff with a university degree is very high \\
\hline AND & Proportion of $30-50$ age employees is medium \\
\hline THEN & Employee's knowledge degree is $(\mathrm{G})$. \\
\hline \multicolumn{2}{|l|}{ K-1-9 } \\
\hline IF & Proportion of staff with a university degree is very high \\
\hline AND & Proportion of $30-50$ age employees is high \\
\hline THEN & Employee's knowledge degree is (VG). \\
\hline
\end{tabular}

Most of the indicators are obtained from "A guideline for intellectual capital statements" [1] and others are determined by experts. Like the evaluation model for intellectual capital proposed by Tai and Chen [3], we use a classification for intellectual capital components (as shown in Figure 4), and we evaluate each components through its importance degree and performance degree. Then, by combining all these degrees, the overall performance of intellectual capital will be determined (Tables 1 and 2).

$\left(b_{2}\right)$ Fuzzy Knowledge Base. The knowledge base represents the knowledge related to the problem domain. A subset of knowledge base is the fact base, which contains both symbolic information and numeric information [18]. Factual 


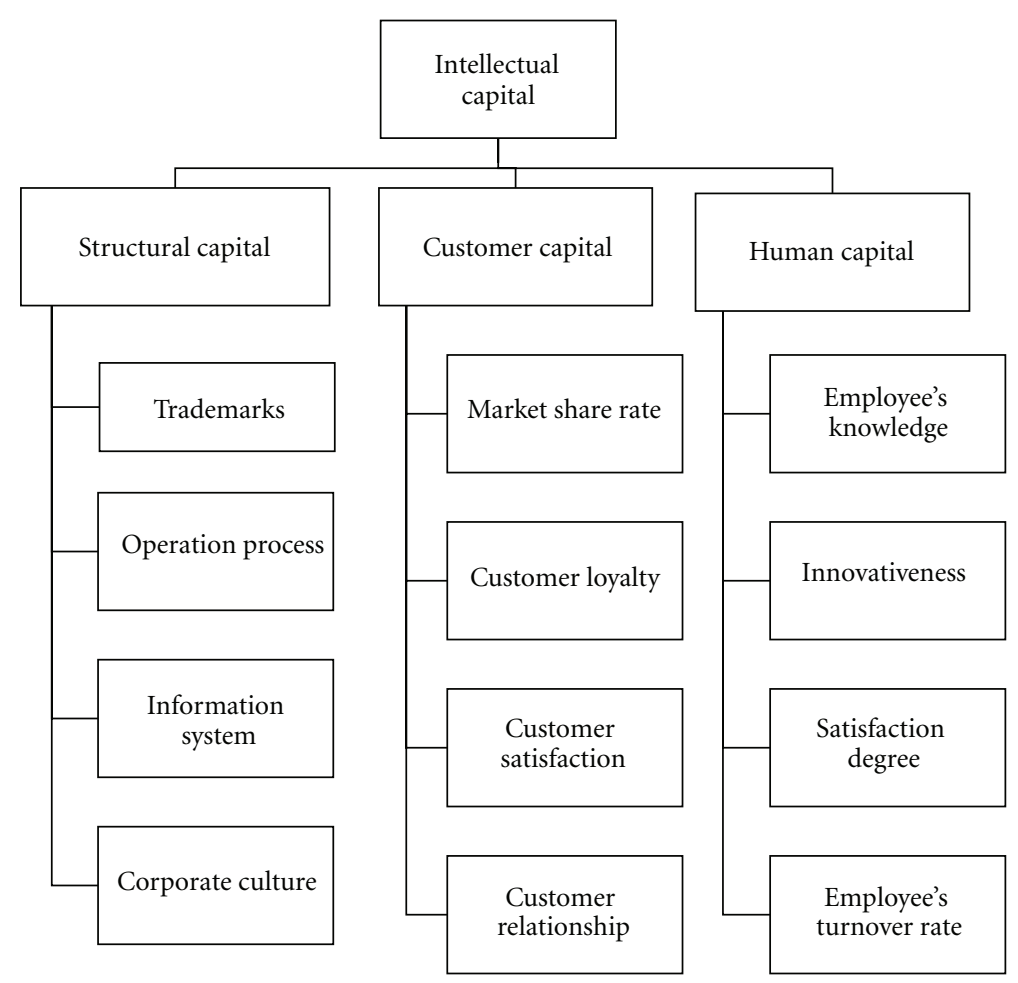

FIGURE 4: Components of intellectual capital (revised from [3]).

knowledge or observed system state or facts in a knowledgebased system are expressed as fact base. A notation of observed system state is

$$
X_{1} \text { isr } A_{1}^{*} \text { AND } X_{2} A_{2}^{*} \text { AND } \cdots \text { AND } X_{n} \text { isr } A_{n}^{*} \text {, }
$$

where "isr" is a short form for "is contained in", "is similar to", "is compatible to", and so forth [18]. In short, it is usually expressed as

$$
A^{*}=A_{1}^{*} \text { AND } A_{2}^{*} \text { AND } \ldots \text { AND } A_{n}^{*}
$$

The user of an expert system inputs the factual knowledge and chooses the linguistic terms for observed states of the system [18]. For example, in proposed expert system in this paper, an observed system state is as follows: Proportion of staff with a university degree isr high and proportion of $30-50$ age employees isr medium

or in short notation:

$$
\text { High AND Medium }
$$

Another part of the knowledge base is rule bases which contain heuristics. They are used by domain experts to diagnose, predict, control, and so forth a system behavior [18]. Experts of intellectual capital domain use heuristics to evaluate components of intellectual capital. A notation of rule-base is

IF $X_{1}$ isr $A_{1}^{*}$ AND $X_{2}$ isr $A_{2}^{*}$ AND $\ldots$ AND $X_{n}$ isr $A_{n}^{*}$,

THEN $Y$ isr $B$
For example, in proposed expert system in this paper, an observed system state is as follows: IF Proportion of staff with a university degree isr high AND Proportion of 30-50 age employees isr medium, THEN employee's knowledge degree isr good

During the knowledge acquisition phase, the domain experts provide these rules. The linguistic terms and their membership values and/or functions are also specified in such rules by experts [18].

$\left(b_{3}\right)$ Fuzzy Inference Mechanism. The inference mechanism uses the knowledge base and the rule base for inference and derivation of decisions for given observed facts [18]. The inference mechanism which we use in this paper is data driven or forward chaining. Forward chaining is an inference strategy that begins with a set of known facts, derives new facts using rules whose premises match the known facts and continues this process until a goal state is reached or until no further rules have premises that match the known or derived facts (Figure 5) [20]. For example, in this paper to model evaluation procedure of employee's knowledge capital in a forward chaining rule-based expert system (Figure 5), system's rules are as follows.

We assert the following facts into the working memory as supplied by sample company's experts.

(i) Proportion of staff with a university degree is high.

(ii) Proportion of 30-50 age employees is medium.

(iii) Total training costs/total payroll expenses are high. 
TABLE 2: Fuzzy rule set for employee's knowledge importance degree.

$\mathrm{K}-2-1$

IF Total training costs/total payroll expenses are very low

THEN

$\mathrm{K}-2-2$

IF Total training costs/total payroll expenses are low

THEN Employee's knowledge is unimportant for company.

$\mathrm{K}-2-3$

IF

AND

AND

THEN

K-2-4

IF

AND

AND Number of employees being trained as project managers/total employees is low

THEN

. .

K-2-5

IF

AND

AND

THEN

K-2-6

IF

AND

AND

THEN

K-2-7

IF

AND

AND

THEN

K-2-8

IF

AND

AND

THEN

Total training costs/total payroll expenses are medium

Number of employees with a competency development plan/total employees is low

Number of employees being trained as project managers/total employees is low

Employee's knowledge is very unimportant for company.

Total training costs/total payroll expenses are medium Number of employees with a competency development plan/total employees is medium

Employee's knowledge is unimportant for company.

Total training costs/total payroll expenses are medium

Number of employees with a competency development plan/total employees is low

Number of employees being trained as project managers/total employees is medium

Employee's knowledge is unimportant for company.

Total training costs/total payroll expenses are medium

Number of employees with a competency development plan/total employees is medium

Number of employees being trained as project managers/total employees is medium

Employee's knowledge is (F) for company.

Total training costs/total payroll expenses are high

Number of employees with a competency development plan/total employees is medium

Number of employees being trained as project

managers/total employees is medium

Employee's knowledge is important for company.

Total training costs/total payroll expenses are high

Number of employees with a competency development plan/total employees is high

Number of employees being trained as project

managers/total employees is medium

Employee's knowledge is important for company.

TABle 2: Continued.

K-2-9

IF Total training costs/total payroll expenses are high

AND Number of employees with a competency development plan/total employees is medium

AND Number of employees being trained as project managers/total employees is high

THEN Employee's knowledge is important for company.

K-2-10

IF Total training costs/total payroll expenses are high

AND Number of employees with a competency development plan/total employees is high

AND Number of employees being trained as project managers/total employees is high

THEN Employee's knowledge is very important for company.

$\mathrm{K}-2-11$

IF Total training costs/total payroll expenses are very high

AND Number of employees with a competency development plan/total employees is medium

AND Number of employees being trained as project managers/total employees is medium

THEN Employee's knowledge is important for company.

$\mathrm{K}-2-12$

IF Total training costs/total payroll expenses are very high

AND Number of employees with a competency development plan/total employees is high

AND Number of employees being trained as project managers/total employees is medium

THEN Employee's knowledge is very important for company.

K-2-13

IF Total training costs/total payroll expenses are very high

AND Number of employees with a competency development plan/total employees is medium

AND Number of employees being trained as project managers/total employees is high

THEN Employee's knowledge is very important for company.

$\mathrm{K}-2-14$

IF Total training costs/total payroll expenses are very high

AND Number of employees with a competency development plan/total employees is high

AND Number of employees being trained as project managers/total employees is high

THEN Employee's knowledge is very important for company.

(iv) Number of employees with a competency development plan/total employees is medium.

(v) Number of employees being trained as project managers/total employees is medium.

The system takes each rule in turn and checks to see if its premises are listed in the working memory. When the system finds matches for all the premises, it places the rule's conclusion in the working memory. 
TABLE 3: Inputs of fuzzy rule-based expert system for sample company.

\begin{tabular}{|c|c|c|c|}
\hline Criteria & Value & Item & Rating \\
\hline \multirow{13}{*}{$\begin{array}{l}\text { Human } \\
\text { capital }\end{array}$} & & \multirow{4}{*}{$\begin{array}{l}\text { Employee's } \\
\text { knowledge }\end{array}$} & Proportion of staff with a university degree is high \\
\hline & Performance degree & & Proportion of $30-50$ age employees is medium \\
\hline & \multirow{2}{*}{ Importance degree } & & Total training costs/total payroll expenses are medium \\
\hline & & & $\begin{array}{l}\text { Number of employees with a competency development } \\
\text { plan/total employees is medium }\end{array}$ \\
\hline & Importance degree & \multirow[t]{2}{*}{$\begin{array}{l}\text { Employee's } \\
\text { knowledge }\end{array}$} & $\begin{array}{l}\text { Number of employees being trained as project } \\
\text { managers/total employees is medium }\end{array}$ \\
\hline & & & Number of patent claims is low \\
\hline & Performance degree & \multirow[t]{2}{*}{$\begin{array}{l}\text { Employee's } \\
\text { innovativeness }\end{array}$} & $\begin{array}{l}\text { Number of new products introduced during the past } 12 \\
\text { months/total products is medium }\end{array}$ \\
\hline & Importance degree & & Cost of research and development/total turnover is low \\
\hline & & \multirow{3}{*}{ Satisfaction } & Proportion of generally satisfied employees is high \\
\hline & Performance degree & & Number of day absence/total working days is low \\
\hline & Importance degree & & The response rate in staff satisfaction survey is high \\
\hline & Performance degree & \multirow{2}{*}{$\begin{array}{l}\text { Employee's } \\
\text { turnover rate }\end{array}$} & $\begin{array}{l}\text { Number of employees leaving the company/total employees } \\
\text { is low }\end{array}$ \\
\hline & Importance degree & & Employees' total number of seniority/total employees is fair \\
\hline \multirow{10}{*}{$\begin{array}{l}\text { Customer } \\
\text { capital }\end{array}$} & Performance degree & \multirow{2}{*}{ Market share rate } & $\begin{array}{l}\text { Company's sales revenue from market/total sales revenue } \\
\text { available in market is high }\end{array}$ \\
\hline & Importance degree & & $\begin{array}{l}\text { Marketing initiative is of a considerable amount of } \\
\text { importance for the company }\end{array}$ \\
\hline & Performance degree & \multirow[b]{2}{*}{ Customer loyalty } & longevity of customer relationship is medium \\
\hline & Importance degree & & $\begin{array}{l}\text { Number of repeat customers buying the brand / total } \\
\text { customers is of a considerable amount of importance for the } \\
\text { company }\end{array}$ \\
\hline & Performance degree & \multirow{2}{*}{$\begin{array}{l}\text { Customer } \\
\text { satisfaction }\end{array}$} & Proportion of customers who are satisfied is high \\
\hline & Importance degree & & The five or ten customer's proportion of total turnover is fair \\
\hline & Performance degree & \multirow{4}{*}{$\begin{array}{l}\text { Customer } \\
\text { relationship }\end{array}$} & $\begin{array}{l}\text { Company considerably have close contact with customer } \\
\text { during specification of requirements }\end{array}$ \\
\hline & & & $\begin{array}{l}\text { Company advising the customer considerably during the } \\
\text { entire process }\end{array}$ \\
\hline & Importance degree & & Guests sometimes participate in company lunch buffet \\
\hline & & & $\begin{array}{l}\text { Customer representatives sometimes participate at } \\
\text { company's conferences }\end{array}$ \\
\hline \multirow{7}{*}{$\begin{array}{l}\text { Structural } \\
\text { capital }\end{array}$} & $\begin{array}{l}\text { Performance and } \\
\text { Importance degree }\end{array}$ & Trademark & $\begin{array}{l}\text { Company has a distinctive sign or indicator to distinguish its } \\
\text { products or services from those of other entities }\end{array}$ \\
\hline & Performance degree & \multirow{2}{*}{ Operation process } & $\begin{array}{l}\text { The proportion of procedures described or proportion of } \\
\text { instruction described is fair }\end{array}$ \\
\hline & Importance degree & & $\begin{array}{l}\text { Standard operating procedure is of considerable importance } \\
\text { for the company }\end{array}$ \\
\hline & Performance degree & \multirow{2}{*}{$\begin{array}{l}\text { Information } \\
\text { system }\end{array}$} & $\begin{array}{l}\text { Proportion of updated knowledge documents on the intranet } \\
\text { is fair }\end{array}$ \\
\hline & Importance degree & & Its costs are high \\
\hline & Performance degree & \multirow{2}{*}{ Corporate culture } & $\begin{array}{l}\text { Employees are averagely identified with company's } \\
\text { perspective }\end{array}$ \\
\hline & Importance degree & & $\begin{array}{l}\text { Having values, faith, and behavior criterions which are } \\
\text { approved and shared by all the staff is of considerable } \\
\text { importance for the company }\end{array}$ \\
\hline
\end{tabular}




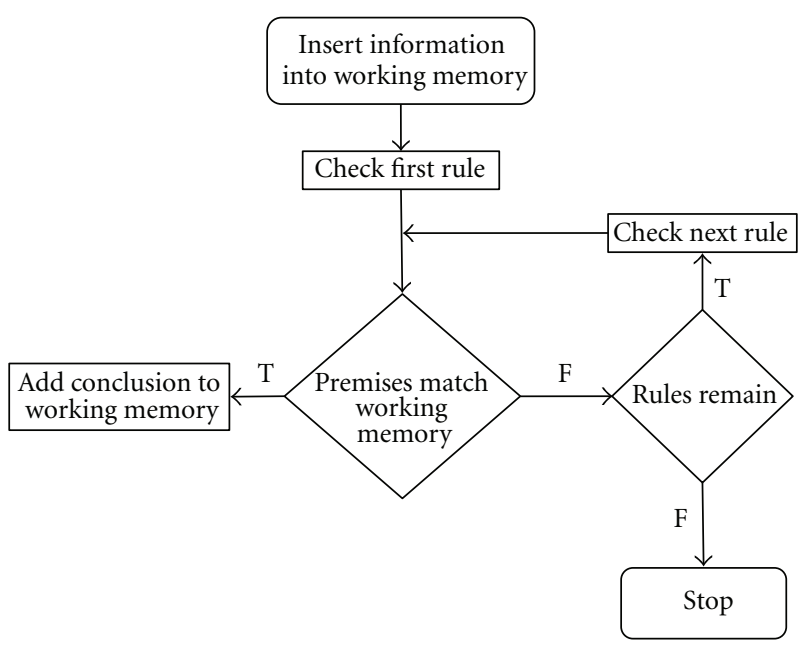

Figure 5: Forward chaining inference process [20].

From the initial information entered into the working memory, the system concludes new information.

(1) Employee's knowledge degree is good.

(2) Employee's knowledge is important for company.

Since the proposed expert system is a fuzzy expert system which uses linguistic variables, a fuzzy inference should be used to evaluate employee's knowledge capital.

Fuzzy Inference. The conjunctive combination of antecedent memberships is executed and projected to the conclusion part of each rule to determine the degree of membership on its consequent [18]. In this paper, we used Mamdani type of linguistic model inference as follows.

Step 1. The antecedent of each rule is evaluated. When the antecedent of rule has more than one part, fuzzy intersections ( $t$-norms) and fuzzy unions ( $t$-conorms) are applied to obtain a single membership value. Fuzzy intersection refers to AND, that we interpret it by Yager $t$-norm in this paper. Hence, intersection of two fuzzy sets $A$ and $B$ defined on $X$ is given as

$\mu_{A \wedge B}(X)=1-\min \left(1,\left(\left(1-\mu_{A}(x)\right)^{p}+\left(1-\mu_{B}(x)\right)^{P}\right)^{1 / P}\right)$.

Fuzzy union refers to OR, that we interpret it by Yager $t$ conorm in this paper. So, union of two fuzzy sets $A$ and $B$ defined on $X$ is given as

$$
\mu_{A \vee B}(X)=\min \left(1,\left(\mu_{A}(x)^{p}+\mu_{B}(x)^{P}\right)^{1 / P}\right) .
$$

Step 2. The consequent of each rule is given as a fuzzy set, and the antecedent value has obtained in Step 1. To obtain a new fuzzy set, we apply a fuzzy implication operator. We use minimum operator which cuts the consequent's membership function (Figure 6).

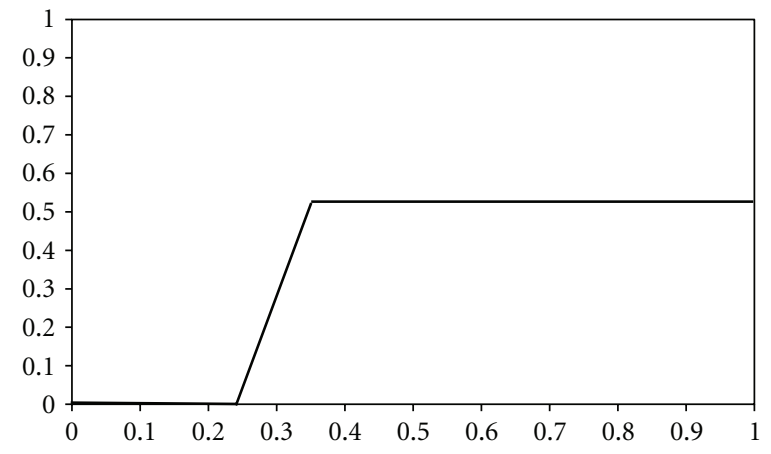

Figure 6: Obtaining each rule conclusion.

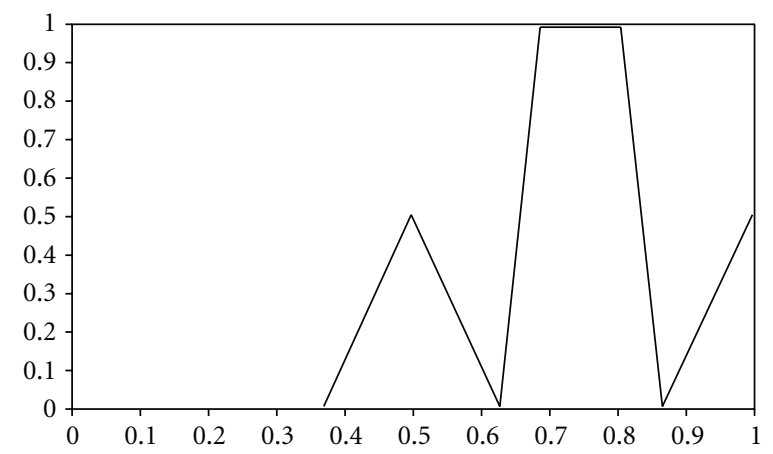

Figure 7: Output result for employee's knowledge performance.

Step 3. The outputs obtained for each rule are combined to a single fuzzy set, using Yager $s$-norm (8).

The last subprocess in a fuzzy expert system is defuzzification. The fuzzy value needs to be converted to a crisp value.

Defuzzification. The overall output fuzzy set is converted into a crisp number on the base variable domain [18]. In this model we used Yager defuzzification method (9).

$$
Z=\frac{\int_{z}\left[\mu_{A}(z)\right]^{w} z d z}{\int_{z}\left[\mu_{A}(z)\right]^{w} d z} .
$$

For example, to define the performance degree of employee's knowledge, the fuzzy inference mechanism is as follows.

System 1. proportion of staff with a university degree is (1) very low, (2) low, (3) fair, (4) high, and (5) very high.

Assume that a user chooses high, then system goes to rules k-1-4 and k-1-5, for second premise of rules k-1-4 and k-1-5.

System 2. Proportion of $30-50$ age employees is (1) low, (2) medium, and (3) high.

Assume that a user chooses medium. Using Mamdani inference with Yager $s$-norm and $t$-norm, and the output is as shown in Figure 7. 


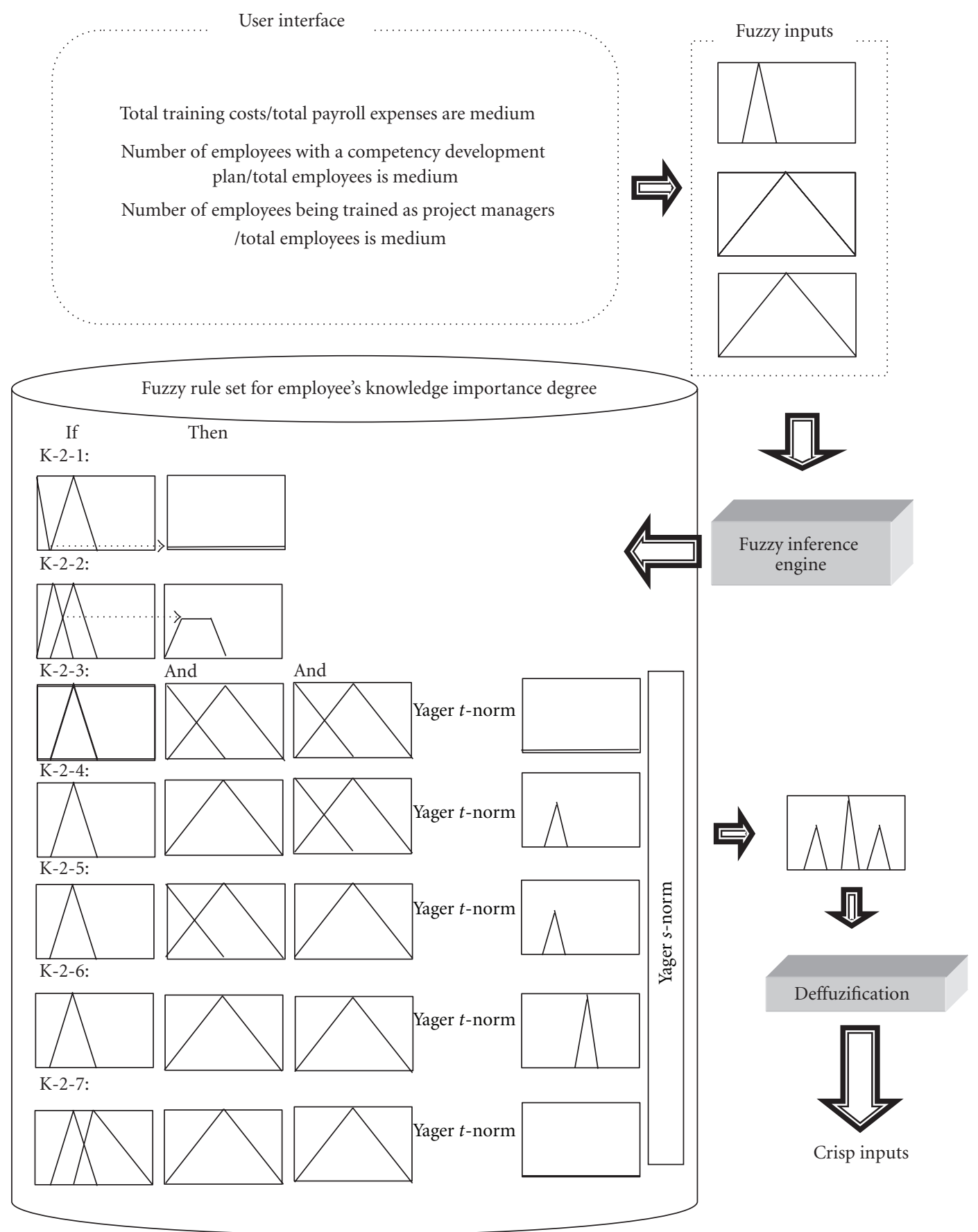

FIGURE 8: Sample procedure for measuring employee's knowledge with proposed fuzzy expert system.

By defuzzifying employee's knowledge, performance degree is 0.7038 . Sample procedure for measuring employee's knowledge performance in proposed fuzzy expert system is as shown in Figure 8.

$\left(b_{4}\right)$ User Interface. In many cases, the disappointing history, that reasoning systems have had can be traced to a lack of respect for the user. The successful systems strive to use operational techniques and decision processes with which users are comfortable. Otherwise, frustrated users will shut the system and quickly return to their old way of doing things. The user interface must be at least able to display and update system message or problem results comprehensibly [21]. In the proposed expert system for evaluating intellectual capital, a user is provided an interactive interface that acquires the information about company through asking questions from them. In Figure 9 a view of evaluation panel for employee's knowledge capital is shown. 


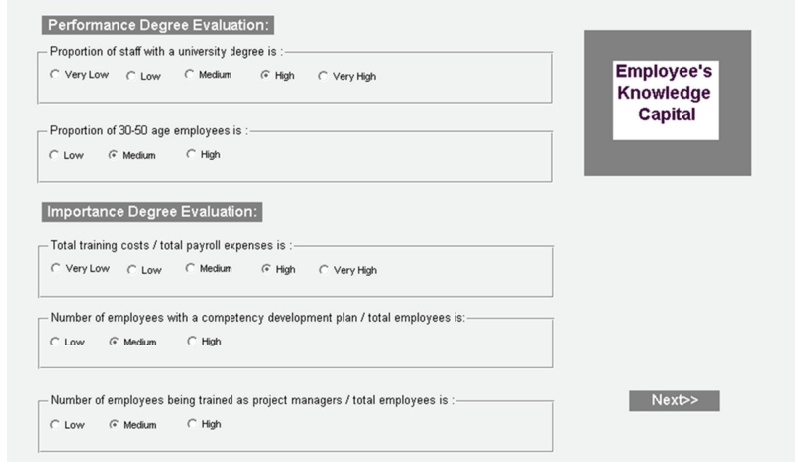

Figure 9: A view of the proposed model interface.

\section{Case Study}

To evaluate applicability of the proposed fuzzy expert system, it is implemented in an industrial company which its activity is to design, source, assemble, install, and commission control systems, precision instrumentation, and electrical systems for power plants as well as mining and process industries. This company has a large number of experts in different fields, and intellectual capital plays an important role in it. Thus, using an expert system which helps managers to handle and understand the status of intellectual capital efficiently and effectively is of great importance in this company.

Initially managers answer the questions asked by the system to determine performance degree and importance degree of each item using linguistic terms ( shown in Table 3 ).

The Total performance of every element is produced by multiplying performance degree by importance degree of each element. Hence, the overall performance of intellectual capital for a company is equal to the summation of all elements' total performance degree.

The overall degree of employee's knowledge is 0.3593 which results by multiplication of performance degree and importance degree of employee's knowledge. According to fuzzy sets on employee's knowledge (similar to Figure 3), 0.3593 is a member of "Low" fuzzy set with 0.2035 membership value and is a member of "Medium" fuzzy set with 0.7965 membership value. Thus, employee's knowledge capital of company is medium $(0.7965>0.2035)$. Employee's performance or human capital performance is evaluated through employee's knowledge, employee's innovativeness, employee's satisfaction, and employee's turnover rate. University degree, age, training costs, and competency development plan are used for evaluating employee's knowledge. Number of patent claims, number of new products introduced during past 12 months, and cost of research and development are used for evaluating employee's innovativeness. By adding more factors into each item, employee's performance would be evaluated more precisely.

The overall performance degree of intellectual capital which is summation of the crisp degree for each element is equal to 3.7989 (scale $0-11$. If all the intellectual items of a company are in best degree, the overall performance of intellectual capital will be 11).

All the previous work in assessing intellectual capital was based on expert judgment of every intellectual item. Experts evaluate every intellectual item using linguistic variables. This kind of evaluation largely depends on expert's concept about intellectual items, which can lead to misevaluation in many cases and finally unreliable results. So, it is better to determine indicators which affect every intellectual item. In this way, a set of rule sets is defined which links indictors to each item, and by evaluating the indictors by experts, each intellectual item is evaluated. The proposed expert system in this paper uses a set of rules to evaluate company's intellectual capital items performance and provides companies more reliable results which are independent of individual's judgment.

\section{Conclusions and Future Works}

In this paper, a fuzzy rule-based expert system is proposed to reveal and evaluate overall performance degree of intellectual capital. Through using the proposed expert system, managers can understand the enterprise situation in every item of intellectual capital even if they do not know exactly what every item means, and they also understand whether each item is important for them in decision making or not. Moreover, using linguistic terms for items evaluation leads to more accurate judgment. Recent proposed model [3] asked expert the performance degree and importance degree of each intellectual capital item. In this way, there is always the risk that experts do not have a clear concept for every item in mind and his/her judgments will be done with some inaccuracy. Thus, using a fuzzy expert system which can help experts to improve his/her judgments is useful.

A suggestion for future studies is concerned is with different kinds of membership functions for linguistic terms to find the best one. Finally, the model is seen as open for future extension and development, especially extending the expert system by adding more precise and detailed rules to evaluate intellectual capital performance more accurately.

\section{References}

[1] Danish Agency for Trade and Industry, A Guideline for Intellectual Capital Statements - A Key to Knowledge Management, 2000.

[2] K. M. Wiig, "Integrating intellectual capital and knowledge management," Long Range Planning, vol. 30, no. 3, pp. 399405, 1997.

[3] W. S. Tai and C. T. Chen, "A new evaluation model for intellectual capital based on computing with linguistic variable," Expert Systems with Applications, vol. 36, no. 2, pp. 3483-3488, 2009.

[4] M. Fasanghari, M. Mohamedpour, and A. Abdollahi, "Assessing intellectual capital with fuzzy expert system," in Proceedings of the 4th International Conference on Networked Computing and Advanced Information Management (NCM '08), pp. 278-283, September 2008.

[5] R. Petty and J. Guthrie, "Intellectual capital: literature review," Journal of Intellectual Capital, vol. 7, no. 2, pp. 254-271, 2006. 
[6] M. Sugeno and T. Yasukawa, "Fuzzy-logic-based approach to qualitative modeling," IEEE Transactions on Fuzzy Systems, vol. 1, no. 1, pp. 7-31, 1993.

[7] L. Edvinsson and M. S. Malone, Intellectual Capital: Realizing Your Company's True Value by Finding Its Hidden Brainpower, Harper Business, New York, NY, USA, 1997.

[8] T. A. Stewart, Intellectual Capital: The New Wealth of Organizations, Currency, New York, NY, USA, 1998.

[9] K. E. Sveiby, The New Organizational Wealth: Managing and Measuring Knowledge-Based Assets, Berrett-Koehler, San Francisco, Calif, USA, 1997.

[10] L. Edvinsson, "Developing intellectual capital at Skandia," Long Range Planning, vol. 30, no. 3, pp. 366-321, 1997.

[11] J. Liebowitz and K. Wright, "Does measuring knowledge make cents?” Expert Systems with Applications, vol. 17, no. 2, pp. 99103, 1999.

[12] Organization for Economic Co-operation and Development (OECD), Guidelines and instructions for OECD Symposium, Intellectual Symposium Measuring Reporting Intellectual Capital: Experiences, Issues, and Prospects OECD, Amsterdam, The Netherlands, Paris, France, 1999.

[13] P. N. Bukh, H. T. Larsen, and J. Mouritsen, "Constructing intellectual capital statements," Scandinavian Journal of Management, vol. 17, no. 1, pp. 87-108, 2001.

[14] J. Chen, Z. Zhu, and H. Xie, "Measuring intellectual capital: a new model and empirical study," Journal of Intellectual Capital, vol. 5, no. 1, pp. 195-212, 2004.

[15] J. P. Ignizio, Introduction to Expert Systems: The Development and Implementation of Rule-Based Expert Systems, McGrawHill, 1991.

[16] A. Abraham, Rule-Based Expert Systems, Oklahoma State University, Stillwater, Okla, USA, 2005.

[17] L. A. Zadeh, "Outline of a new approach to the analysis of complex systems and decision processes," IEEE Transactions on Systems, Man, and Cybernetics, vol. 3, p. 2844, 1973.

[18] H. J. Zimmerman, Practical Applications of Fuzzy Technologies, Kluwer Academic Publishers, 1999.

[19] A. Celikyilmaz and I. B. Türkșen, Modeling Uncertainty with Fuzzy Logic: With Recent Theory and Applications, Springer, 2009.

[20] J. Durkin, Expert Systems: Design and Development, Macmillan, 1994.

[21] C. Mount and T. W. Liao, "Prototype of an intelligent failure analysis system," in Proceedings of the 4th International Conference on Case-Based Reasoning (ICCBR '01), pp. 716731, Vancouver, BC, Canada, 2001.

[22] J. E. Burge, "Knowledge Elicitation Tool Classification," 2011, http://web.cs.wpi.edu/ jburge/thesis/kematrix.html\#_Toc417957386. 

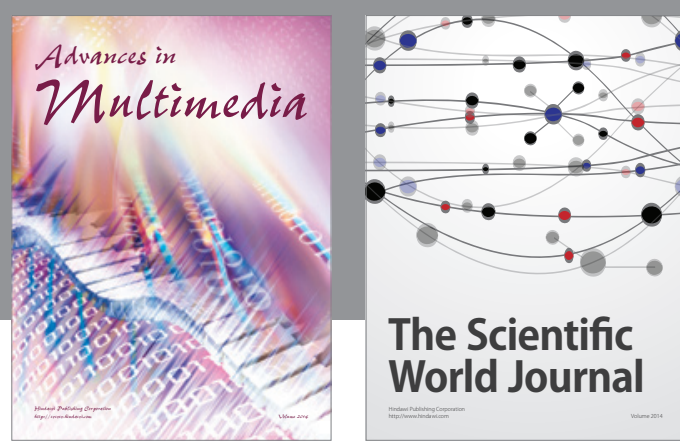

The Scientific World Journal
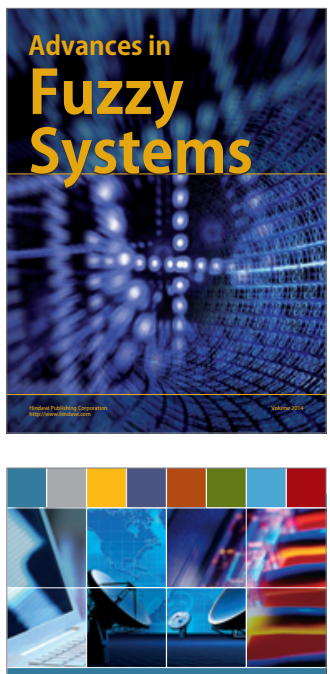

Computer Networks and Communications
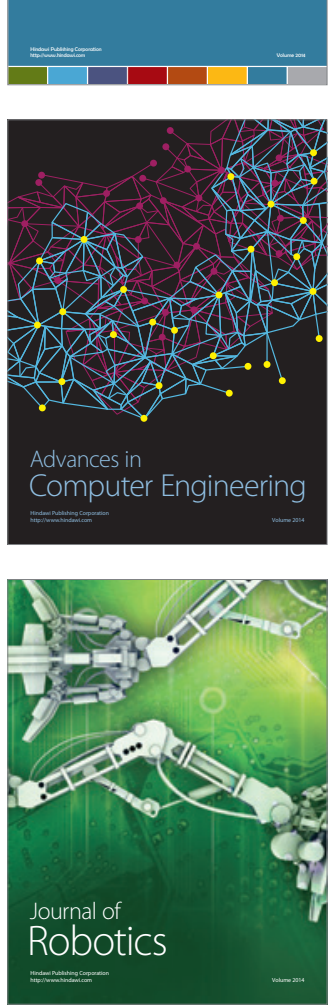
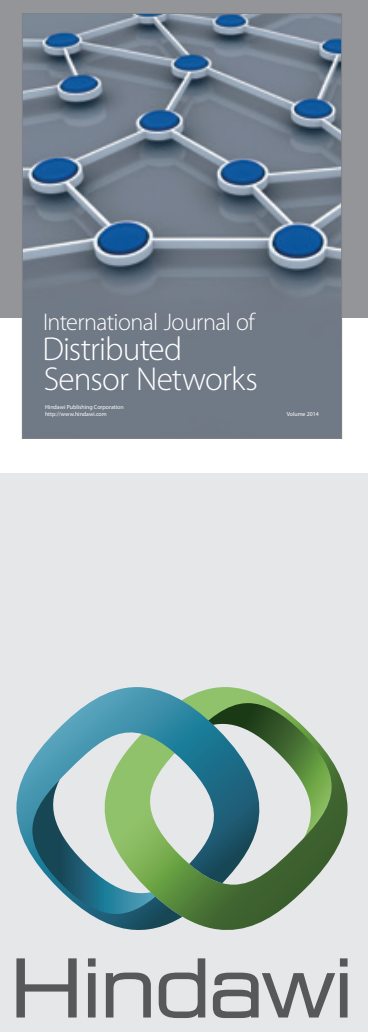

Submit your manuscripts at

http://www.hindawi.com
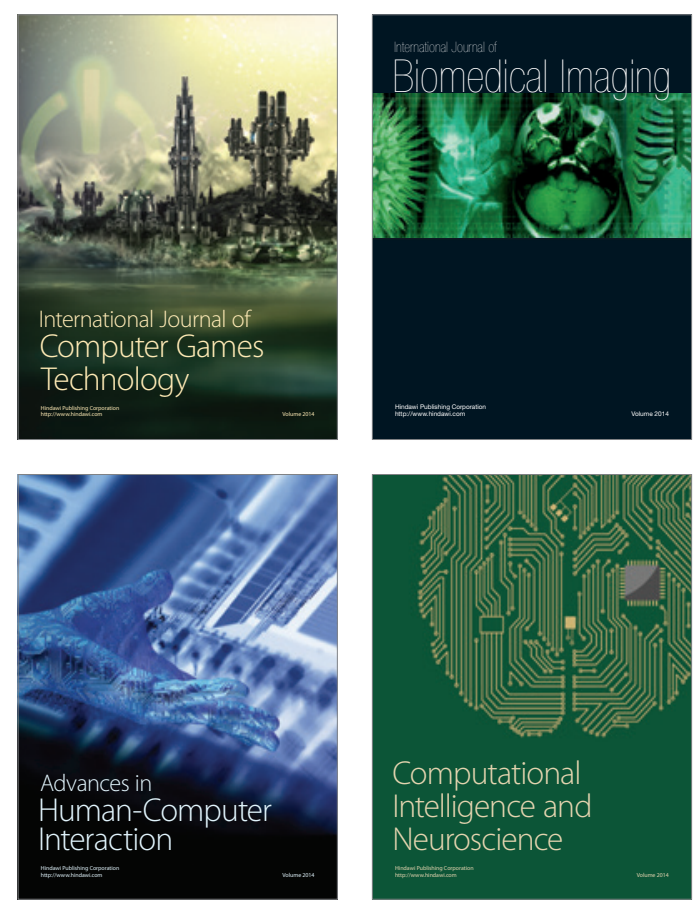
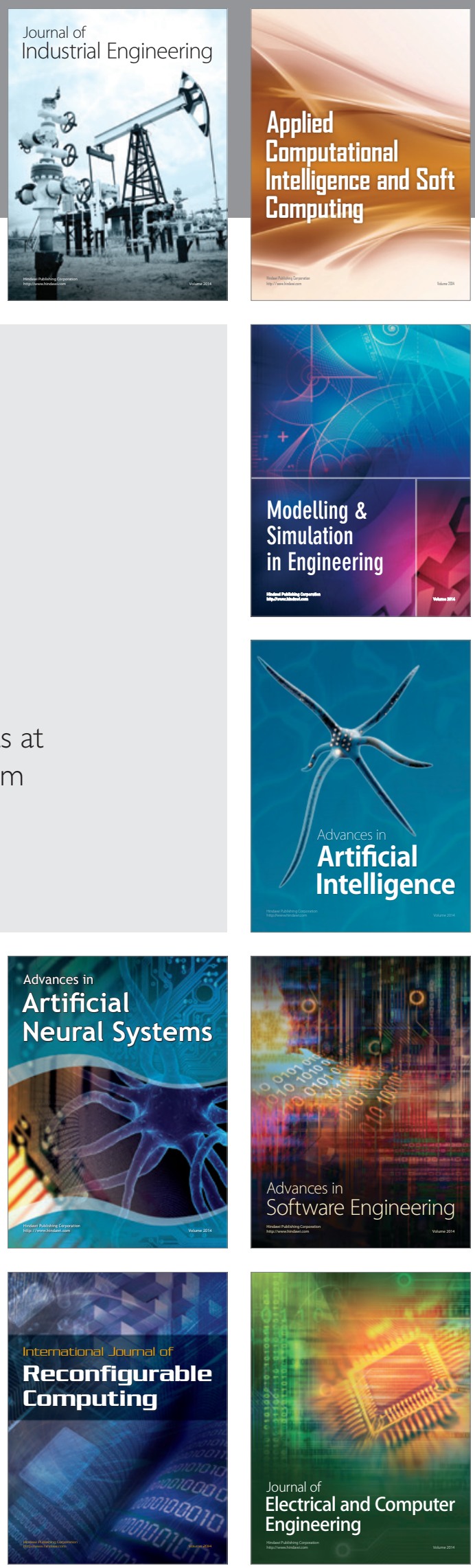